\title{
Effect of Bosu Ball Versus Swiss Ball on Core Strength in Overweight and Obese Post Menopausal Working Women
}

\author{
Ankita Mane', Amrutkuvar Rayjade ${ }^{2}$ \\ ${ }^{1}$ Intern, Faculty of Physiotherapy, ${ }^{2}$ Associate Professor, Department of Musculoskeletal Sciences, Faculty of \\ Physiotherapy, Krishna Institute of Medical Sciences Deemed to be University, Karad, Maharashtra, India
}

\begin{abstract}
Background: During post menopausal period, many changes take place in women physiologically. Among them core muscle weakness, pelvic floor dysfunction. There can be some measures taken for improving core strength in women. It leads to the cessation of ovarian estrogen production concurrent to the deterioration of muscle function. So this study is an effort made to check either bosu ball is effective or swiss ball.
\end{abstract}

\begin{abstract}
Aims and Objective: To find the effect of bosu ball versus swiss ball for core strengthening in post menopausal women. Objectives : to compare effect of bosu ball and swiss ball for core strengthening in post menopausal women.
\end{abstract}

Subject and Methodology: The experimental study was carried over a period of 12 weeks. Sampling size includes total 24 subjects. 12 in each group, materials used were bosu ball, Swiss ball, pen, paper. Study was conducted in Krishna college of physiotherapy.

Result: And it was found that for bosu ball; before protocol trunk stability test and abdominal curl test was performed and it was found that by $70 \%$ the strength had been improved in population who followed the bosu ball protocol. For trunk stability test the $\mathrm{p}$ value was $<0.0001$ which was extremely significant. For abdominal curl test the $\mathrm{p}$ value was $<0.0001$ which was extremely significant. The results for swiss ball by trunk stability test were, $\mathrm{p}$ value was $<0.22$ which was not significant. For abdominal curl test the $\mathrm{p}$ value was $<0.20$.

Conclusion: Bosu ball was effective than swiss ball.

Keywords: Post menopausal women, bosu ball, swiss ball, core strength.

\section{Corresponding Author:}

\section{Dr. Amrutkuvar Rayjade}

Associate Professor, Department of Musculoskeletal

Sciences, Faculty of Physiotherapy, Krishna Institute

of Medical Sciences Deemed to be University, Karad,

Maharashtra, India

e-mail: maneankita196@gmail.com 


\section{Introduction}

\section{"PAUSE"}

Yes, she just had her menopause.

Yes, she still yearns to live life to the fullest!

What exactly is menopause, Menopause is defined as the time when there has been no menstrual periods for 12 consecutive months ${ }^{(1)}$. Also it occurs when there is complete, or near complete, ovarian follicular depletion of females ovaries. It generally occurs at a median age of 51.4 years and menopause before the age of 40 years is considered abnormal. The months and years leading up to this are called perimenopause. Hot flushes, vaginal dryness, depression, sleep disturbances, joint pain, and cognitive changes are some of the pre warning signs of menopause ${ }^{(1)}$.

Physiologically, a female ovary has the largest number of gametocytes during the $5^{\text {th }}$ month of gestation and has approximately 1 million of gametocytes at birth as women ages normal openings or follicular tubes in the body are closed, which reduces the number of gametocytes. As a result, at the time of menopause a women may have a few thousand or a few hundred gametocytes left. As the ovary produces three hormones: estrogen, progesterone and androgens. Among the estrogens, estrone (E1), estradiol (E2) and estriol (E3) are the three produced estrogens. Estradiol is the most potent natural estrogen and is produced during the monthly menstrual cycle. Fluctuations and deficiencies in estrogen levels cause many of the menopausal signs and symptoms. Natural menopause, pre mature of early menopause, surgical or induced menopause are some of the types of menopause ${ }^{(1)}$.

Strengthening core has become a major trend in rehabilitation. It is a description of the muscular control required around the lumbar spinae to maintain functional stability $^{(2)}$. Core training excluding the diaphragm for old individuals can also improve balance ability. Strength exercises for muscles are therefore hypothesized to help improve balance ability during sitting without support. Contraction of trunk core muscles increases intraabdominal pressure, providing stability and stiffness of the body ${ }^{(3)}$. The core programme should progressed and planned gradually as exercising the core muscles is more than trunk strengthening ${ }^{(4)}$. A variety of core exercises are used to develop core strength and core stability which are believed to be important for women. Curls up and sit ups are the most common abdominal exercises. Unstable surfaces, such as swiss ball, bosu ball have been used to increase the neuromuscular stress in the core muscle compared with a stable surface. In rehabilitation, BOSU and swiss ball may be beneficial because the lower back is supported while performing on flat surface. ${ }^{(5)}$

Effect of core and treadmill training on skeletal mineralization in post menopausal women is important ${ }^{(7)}$. BOSU ball consists of an inflated rubber hemisphere attached to a rigid platform. It has a flat surface and a hemisphere. The hemisphere is half- filled with air, which provides enough instability that prompts the recruitment of all the core muscles. And the flat surface provides stability to do the exercises with maximum precision. The device is used for balance training. Swiss ball, is primarily benefit of exercising with an exercising directly on a hard flat surface is that the body responds to the instability of the ball to remained balanced, engaging many more muscles.. Swiss ball abdominal crunch is one of the exercise for core strengthening ${ }^{(8)}$. The greatest benefit of moving an exercise onto an unstable surfaced is achieving a greater activation of the core musculature ${ }^{(9)}$. An unstable surface increases activation of the rectus abdominis muscle and allows for greater activity or exercises when compared to a stable surface. Core stability exercises on and off a swiss ball(10), Exercise such as a curl ups on an exercise ball yields a greater amount of electromagnetic graph compared to exercise on a stable platform. Performing standard exercises, such as a push up on an unstable surface can be used to increase activation of core trunk stabilizers and in turn provide increased trunk strength and greater resistance to injury.

Aims: To find the effect of bosu ball versus swiss ball for core strengthening in post menopausal women.

\section{Objectives:}

1. To determine effect of bosu ball in post menopausal women.

2. To determine effect of swiss ball in post menopausal women.

3. To compare effect of bosu ball and swiss ball for core strengthening in post menopausal women.

Material: The experimental study was carried over a period of 12 weeks. Sampling size includes total 24 subjects. 12 in each group, materials used were bosu ball, swiss ball, pen, paper. Study was conducted in Krishna college of physiotherapy. 


\section{Methodology}

The ethical clearance was taken from the institutional ethical committee of Krishna institute of medical sciences "deemed to be" university karad. A experimental study was conducted over period of 12 weeks in post menopausal women in musculoskeletal department of Krishna college of physiotherapy. Prior consent was taken and study was explained to the participants. The participant were attended and assessed personally with 15 to 30 mins of session per day. Major outcome measure were swiss ball and bosu ball.

\section{Procedure: Exercises on swiss ball:}

1. Stability ball crunch: ask the subject to lie face up on the ball, with the ball under low back. Keep feet on the floor, hip width apart, and behind ears. Brace core, tighten glutes and slowly crunch upper body upward, raising shoulders off the ball and tucking chin to chest. Slowly lower upper body down to return to start.

2. Stability ball oblique crunches: procedure same as above. Brace core by pulling navel toward spine. Tightens glutes and slowly crunch up and to the right. Ask to lift shoulder blades off the ball and rotate upper body to the right. Lower the back down and repeat on the left side.

3. Ball crunch: legs elevated, lie on back,calves on top of the exercise ball and arms across chest. Roll shoulder blades up and lower back down after a short pause. To avoid strain in neck, ask the subjects to look straight up instead of looking at knees.

\section{Exercises on Bosu ball:}

1. Bosu one leg bridge: ball flat on floor. Lie down on back and place feet on top of the ball. Raise one leg towards the ceiling and push hips up again before touching the floor. Repeat for 10-15 repetitions on each leg.

2. Crunch: lay on bosu ball and bring feet towards the body. Place hands behind head, engage the abs, and slowly raise the upper body (looking upwards).

3. Sit ups: lay over the bosu ball. Raise arms towards the ceiling, engage the abs, and then raise the upper body and towards feet. Hold for a secs and return to starting position.

\section{Inclusion Criteria:}

1. Age group beyond 45-50 years.
Medico-legal Update, October-December 2020, Vol. 20, No. 4

71

2. Post menopausal women who were willing to participate.

3. Only working women are considered for the study.

4. BMI with overweight and obese grade I, grade II

\section{Exclusion Criteria:}

1. Recent fractures

2. Soft tissue injuries

3. Episodes of mechanical or specific back pain.

4. Carcinoma

5. Cardiovascular conditions.

\section{Limitation:}

1. Only post menopausal women are taken.

2. Only working women were included

3. Only grade I, II obese women were included .

\section{Suggestions and Recommendations:}

1. This study can be done on large populations.

2. This study can be made more precise withmore details.

3. Non working women can also be included.

Source of Funding: Krishna Institute of Medical Sciences.

\section{Conflict of Interest: Nil}

Data Analysis:

Table No 1: Trunk Stability Test for Bosu Ball

\begin{tabular}{|l|c|}
\hline & Trunk Stability Test \\
\hline Before Protocol & $30 \%$ \\
\hline After Protocol & $70 \%$ \\
\hline
\end{tabular}

$\mathrm{P}$ value $<0.0001$ in relation to protocol before and after is extremely significant.

\section{Interpretation:}

Table No 2: Abdominal Curl Test for Bosu Ball

\begin{tabular}{|l|c|}
\hline & Abdominal Curl Test \\
\hline Before Protocol & $30 \%$ \\
\hline After Protocol & $70 \%$ \\
\hline
\end{tabular}

$\mathrm{P}$ value $<0.20$ abdominal curl test in relation to before and after protocol is notsignificant. 
Interpretation:

Table No 3: Trunk Stability Test for Swiss Ball

\begin{tabular}{|l|c|}
\hline & Trunk Stability Test \\
\hline Before Protocol & $45 \%$ \\
\hline After Protocol & $55 \%$ \\
\hline
\end{tabular}

P value $<0.22$ trunk stability test in relation to before and after protocol is very significant.
Interpretation:

Table No 4: Abdominal Curl Test for Swiss Ball

\begin{tabular}{|l|c|}
\hline & Abdominal Curl Test \\
\hline Before Protocol & $45 \%$ \\
\hline After Protocol & $55 \%$ \\
\hline
\end{tabular}

$\mathrm{P}$ value $<0.20$ of abdominal curl test in relation to before and after protocol is not significant.

\section{Interpretation:}

Table No 5: Summary of Tests

\begin{tabular}{|l|c|c|c|c|}
\hline & Bosu Ball Before & After & Swiss Ball Before & After \\
\hline Trunk Stability Test & $30 \%$ & $70 \%$ & $45 \%$ & $55 \%$ \\
\hline Abdominal Curl Test & $30 \%$ & $70 \%$ & $45 \%$ & $55 \%$ \\
\hline
\end{tabular}

Table No 6: Summary of Results

\begin{tabular}{|c|c|c|c|c|c|}
\hline & & $\begin{array}{l}\text { Standard } \\
\text { Deviation }\end{array}$ & P Value & T Value & Interference \\
\hline \multirow{4}{*}{ Bosu Ball } & Before Tst & 1.9 & $<0.0001$ & 9.62 & \multirow{2}{*}{ Extremely significant } \\
\hline & After Tst & 1.6 & & & \\
\hline & Before Act & 2.2 & $<0.0001$ & 6.99 & \multirow{2}{*}{ Extremely significant } \\
\hline & After Act & 4.4 & & & \\
\hline \multirow{4}{*}{ Swiss Ball } & Before Tst & 1.11 & $<0.22$ & 1.26 & \multirow{2}{*}{ Not significant } \\
\hline & After Tst & 0.66 & & & \\
\hline & Before Ast & 0.68 & $<0.20$ & 1.30 & \multirow{2}{*}{ Not significant } \\
\hline & After Ast & 0.54 & & & \\
\hline
\end{tabular}

\section{Result}

After analyzing the data, significant effect was found on post menopausal women after the protocol by using bosu ball and swiss ball respectively. It was found that bosu ball was effective than swiss ball based on the tests such trunk stability test and abdominal curl up test. Before and after protocol reading were assessed accordingly. The results were as follows: Three exercises in each group were given i.e stability ball crunch, stability ball oblique crunch, and ball crunch on swiss ball and one leg bridge, crunches, and sit ups on bosu ball. The study was carried for 12 weeks. And it was found that for bosu ball; before protocol trunk stability test and abdominal curl test was performed and it was found that by $70 \%$ the strength had been improved in population who followed the bosu ball protocol. For trunk stability test the $p$ value was $<0.0001$ which was extremely significant, $t$ value was 9.62, standard deviation before and after protocol was 1.9 and 1.6 respectively. For abdominal curl test the $\mathrm{p}$ value was $<0.0001$ which was extremely significant, $\mathrm{t}$ value was 6.99 and standard deviation before and after was 2.2 and 4.4 respectively. The results for swiss ball by trunk stability test were, $\mathrm{p}$ value was $<0.22$ which was not significant, $t$ value was 1.26 , standard deviation before and after the protocol were 1.11 and 0.66 respectively. For abdominal curl test the $\mathrm{p}$ value was $<0.20$, $\mathrm{t}$ value was 1.30 and standard deviation before and after the protocol were 0.68 and 0.54 respectively. 


\section{Discussion}

Menopause is defined as the time when there has been no menstrual periods for 12 consecutive months ${ }^{(1)}$. Also it occurs when there is complete, or near complete, ovarian follicular depletion of females ovaries. Therefore, the objective of this study was to find effect of bosu ball versus swiss ball exercises training and find whether bosu ball is effective or swiss is effective.

The study shows that how much the effect is caused by which treatment protocol in post menopausal women. The study is one of its kind providing basic information regarding the effect of bosu ball versus swiss ball on core strength in overweight and obese post menopausal working women. To our knowledge no such study is conducting to find out the effect of bosu ball versus swiss ball on core strength in overweight and obese post menopausal working women.

Two tests were carried out such as trunk stability test and abdominal curl test which were conducted among 24 subjects, 12 in each group over a period of 12 weeks. It was studied in the population including working women in any field. They were also examined according to the their age beyond 45 years, body mass index ranging from 25 to 39.9 according to the classification discovered by WHO. The results were achieved by performing the tests. In this study Age group beyond 45-50 years was included, only working women were considered and . BMI with overweight and obese grade I, grade II were included. A exercise protocol was given which includes exercises such as Stability ball crunch, Stability ball oblique crunch and ball crunch for swiss ball. bosu one leg bridge, crunch and sit ups for bosu ball were performed. And a significant result was found. After that data analysis was carried. The readings were compared of before and after protocol as follows: based on two tests which were trunk stability test and abdominal curl test to check the core muscle strength. And it was found that for bosu ball; before protocol trunk stability test and abdominal curl test was performed and it was found that by $70 \%$ the strength had been improved in population who followed the bosu ball protocol. For trunk stability test the $\mathrm{p}$ value was $<0.0001$ which was extremely significant, $t$ value was 9.62, standard deviation before and after protocol was 1.9 and 1.6 respectively. For abdominal curl test the $\mathrm{p}$ value was $<0.0001$ which was extremely significant, t value was 6.99 and standard deviation before and after was 2.2 and 4.4 respectively. The results for swiss ball by trunk stability test were, $p$ value was $<0.22$ which was not significant, $\mathrm{t}$ value was 1.26 , standard deviation before and after the protocol were 1.11 and 0.66 respectively. For abdominal curl test the $\mathrm{p}$ value was $<0.20, \mathrm{t}$ value was 1.30 and standard deviation before and after the protocol were 0.68 and 0.54 respectively.

In another study "The effects of training by virtual reality or gym ball on pelvic floor muscle strength in postmenopausal women: a randomized controlled trial" which was studied by Martinho N, Silva V. A randomized controlled trial was conducted with 60 postmenopausal women, randomly allocated into two groups: Abdominopelvic training by virtual reality APT_VR ( $\mathrm{n}=30)$ and PFMT using a gym ball - PFMT GB $(n=30)$. Both types of training were supervised by the same physical therapist, during 10 sessions each, for 30 minutes. The outcome endurance was higher in the APT_VR group ( $\mathrm{p}=0.003$; effect size $=0.89$; mean difference $=1.37 ; 95 \% \mathrm{CI}=0.46$ to 2.28 ). Conclusion: Both protocols have improved the overall PFM strength, suggesting that both are equally beneficial and can be used in clinical practice.

In the current study, it was seen that the treatment protocol given on BOSU ball was more effective than the treatment given on swiss ball . Many other etiological factors can be responsible for reduced core strength. however further studies are required with a large sample size to get a deep insight about the effect.

\section{Conclusion}

By this study, it was found that bosu ball was more effective than swiss ball with $\mathrm{p}$ value $<0.0001$ which was extremely significant.

\section{Ethical Clearance:}

\section{References}

1. Saljoughian M. Menopause: changes and challenges. US Pharm. 2018;(1):13-16.

2. Akuthota V, Nadler S. core strengthening. 2004:85 (3 suppl 1): S86-92.

3. Oda H, Sasaki M. Effects of core strength training on core stability. J Phys Ther Sci. 2018 Aug; 30(8): 1014-1018

4. Atle H, Anderson V, Jansson J. Effects of bosu ball(s) during situps with body weight and added resistance on core muscle activation. 28(12)/35/53522, 2014. 
5. Martinho nm, Silva vr, Carvalho lc. The effects of training by virtual reality or gym ball on pelvic floor muscles strength in post menopausal women, randomized controlled trial. Braz J Phys Ther. http://dx.doi.org/10.1590/bjpt-rbf 2014.0148.

6. Mcbride, JM, Larkin TR, Dayne AM. Effect of absolute and relative loading on muscle activity during stable and unstable squatting. Int J Sports Physical Performed 5:177-183,2010.

7. Mohamed M, Fawaz H, et al. Effect of core and treadmill training on skeletal mineralization in post menopausal osteoporotic women.

8. Sundstrup E, Jakobsen MD. Swiss ball abdominal crunch with added elastic resistance is an effective alternative to training machines. Int J Sports Phys Ther 7:372-380,2012.

9. Vera-garcia FJ, Grenier SG, Mcgill SM. Abdominal muscle response during curl ups on both stable and labile surfaces. Phys Ther 80:564-569,2000.

10. Marshall PW, Murphy BA. Core stability exercises on and off a swiss ball. Arch Phys Med Rehabil. 2005;86:242-249

11. Rafael F, Lewis C, Bell D,. Core muscle activation during swiss ball and traditional exercises. J Orthop Sports Phys Ther 2010.40:265-276.

12. Beim GM, Giraldo JL. Abdominal strengthening exercises: a comparative EMG study. J Sport Rehab. 1997;6:11-20. 